\title{
Tuberculose em caprinos e ovinos abatidos no semiárido da Paraíba, Brasil
}

\author{
Tuberculosis in goats and sheep slaughtered in the \\ semiarid of the Paraiba state, Northeast region of Brazil
}

\author{
Severino Silvano dos Santos Higino', Sônia Regina Pinheiro², Vivianne Cambuí Mesquita Rocha², \\ Gisele Oliveira de Souza ${ }^{2}$, Roseane de Araújo Portela', Clebert José Alves ${ }^{1}$, Sílvio Arruda Vasconcellos ${ }^{2}$, \\ Cristina Corsi Dib ${ }^{3}$, Tatiana Reis do Rosário ${ }^{3}$, Priscilla Anne Melville², Sérgio Santos de Azevedo*
}

RESUMO: O objetivo do presente trabalho foi isolar e tipificar micro-organismos presentes em linfonodos hipertrofiados ou lesões macroscópicas sugestivas de tuberculose colhidos de 12 caprinos e 28 ovinos abatidos no matadouro público do município de Patos, Paraíba. A identificaçáo de micobactérias foi feita com o método PRA (PCR-Restriction Enzyme Analysis). Também foi realizado o exame histopatológico das lesóes. Os órgáos afetados foram fígado, pulmão, glândula mamária, bexiga e linfonodos mediastínicos, mesentéricos, submandibulares, parotídeos, poplíteos, pré-crural, pré-escapular e inguinal superficial. O exame histopatológico apontou a presença de granulomas em $8(20,00 \%)$ animais. Dos 12 caprinos, $1(8,33 \%)$ foi positivo no cultivo de micobactérias, e pelo método PRA o isolado foi classificado como pertencente ao complexo M. tuberculosis. Dois $(7,14 \%)$ ovinos foram positivos para a presença de micobactérias ambientais. Houve isolamento de Corynebacterium pseudotuberculosis em 8 (66,66\%) caprinos e em 17 (60,71\%) ovinos, e isolamento simultâneo de micobactérias e $C$. pseudotuberculosis em $1(8,33 \%)$ caprino e 1 (3,57\%) ovino. O isolamento de micobactéria do complexo $M$. tuberculosis em caprinos no presente trabalho levanta preocupaçóes do ponto de vista de saúde pública, uma vez que profissionais envolvidos na manipulação destes animais, bem como a população consumidora de carne e leite, estão expostos ao risco de infecção.

PALAVRAS-CHAVE: micobacteriose; complexo Mycobacterium tuberculosis; pequenos ruminantes; procedimento laboratorial.
ABSTRACT: The aim of this work was to isolate and characterize microorganisms in hypertrophied lymph nodes or gross lesions suggestive of tuberculosis collected from 12 goats and 28 sheep slaughtered at the public slaughterhouse of Patos municipality, Paraíba State, in the Northeast region of Brazil. The identification of mycobacteria was performed by the PRA method (PCR-Restriction Enzyme Analysis). Histopathological examination of lesions was also performed. Organs affected were liver, lung, mammary gland, bladder and mediastinal, mesenteric, submandibular, parotid, popliteal, precrural, prescapular and superficial inguinal lymph nodes. Histopathological examination showed the presence of granulomas in $8(20.00 \%)$ animals. Of the 12 goats, $1(8.33 \%)$ was positive in the culture of mycobacteria, and by PRA method the isolate was classified as belonging to the $M$. tuberculosis complex. Two (7.14\%) sheep were positive for the presence of environmental mycobacteria. There was isolation of Corynebacterium pseudotuberculosis in 8 (66.66\%) goats and 17 (60.71\%) sheep, and simultaneous isolation of mycobacteria and C. pseudotuberculosis in 1 (8.33\%) goat and 1 (3.57\%) sheep. The isolation of mycobacteria of the $M$. tuberculosis complex in goats in this study raises concerns of public health, as professionals involved in handling these animals and the meat and milk consumers are exposed to the risk of infection.

KEYWORDS: mycobacteriosis; Mycobacterium tuberculosis complex; small ruminants; laboratorial procedure.

'Universidade Federal de Campina Grande (UFCG) - Patos (PB), Brasil.

²Universidade de São Paulo (USP) - São Paulo (SP), Brasil.

${ }^{3}$ Instituto Biológico de São Paulo - São Paulo (SP), Brasil.

*Autor correspondente: ssazevedo@cstr.ufcg.edu.br

Recebido em: 21/11/2011. Aceito em: 25/06/2013 


\section{INTRODUÇÃO}

O Brasil possui grande extensão territorial, oferece ótimas condiçóes para a criaçáo de caprinos e ovinos e está entre os dez países com os maiores rebanhos destas espécies no mundo. Seus rebanhos somados representam 25 milhóes de cabeças, o equivalente a 2,8\% do efetivo mundial, que é de aproximadamente 900 milhôes de animais (BrASIL, 2007).

A pecuária destinada à criação de ovinos vem se expandindo há muito tempo e diversificando a sua exploração. Em condiçóes criatórias brasileiras, antigamente os ovinos eram utilizados apenas para a subsistência familiar, particularmente para produção de lấ e carne. Com a evolução da seleção genética e o desenvolvimento tecnológico percebeu-se que esta espécie poderia ser uma fonte valiosa de renda, não só pela comercializaçáo de seus produtos tradicionais, mas também pela venda do leite e de seus subprodutos (BRITO et al., 2006).

Já os caprinos concentram sua maior população na região Nordeste (aproximadamente $90 \%$ do rebanho) e têm como principais funçóes econômicas a produção de carne e pele, diferente de outros países adiantados, nos quais o produto mais explorado é o leite, devido ao grande potencial desses animais (Quintans, 1995; Cordeiro, 1998).

Evoluindo de criaçóes voltadas para a subsistência, nos últimos anos ocorreram mudanças significativas para a consolidação da cadeia produtiva da ovinocaprinocultura no Brasil. Nesse período, a atividade despertou maior atenção de governantes, técnicos e produtores, acarretando mudanças significativas, destacando-se a intensificação da pesquisa voltada para produção de animais e beneficiamento de seus produtos, crescimento do nível de organizaçáo dos produtores, aumento da absorçáo das novas tecnologias, maior atuação dos agentes financeiros para facilitar o acesso ao crédito e, o mais importante, incremento da demanda por produtos derivados de caprinos e ovinos (Silva, 1998). Entretanto, apesar do impulso mercadológico, a produtividade da ovinocaprinocultura no Brasil ainda é baixa.

Uma das razóes está no regime de manejo da exploraçáo predominantemente extensiva e rudimentar, com alta dependência da vegetação nativa, utilização de raças não especializadas, assistência técnica deficitária, baixo nível de organização e de gestáo da unidade produtiva e, sobretudo, carecimento de controle sanitário efetivo. Desta forma, o mercado vem exigindo maior preocupaçáo sanitária por meio de medidas de biossegurança com exames diagnósticos rápidos e confiáveis. Neste contexto, o estudo da tuberculose é relevante devido às perdas econômicas ocasionadas e à possibilidade de transmissão para os seres humanos. Somase a isso o fato de que a epidemia da infecção pelo HIV é um significante obstáculo para o controle de Mycobacterium bovis em vários países, tendo em vista que o número de casos de tuberculose humana por $M$. bovis vem aumentando nas últimas décadas (Thoen et al., 2006).
A tuberculose caprina é semelhante à bovina (CorRÊA, 1975), mas Cordes et al., (1981), em estudo sobre a observaçáo da tuberculose causada por $M$. bovis, sugeriram que a baixa incidência da tuberculose nesta espécie possa ocorrer devido a falhas no diagnóstico, pois a linfadenite caseosa apresenta lesôes macroscópicas semelhantes às da tuberculose. Tendo em vista que a linfadenite tem ampla distribuição no Brasil e acomete os caprinos (LANGENEGGER et al.,1991), este fato também poderia estar ocorrendo em nossas criações.

Dessa maneira, o objetivo do presente trabalho foi isolar e tipificar micro-organismos presentes em linfonodos hipertrofiados ou lesôes macroscópicas sugestivas de tuberculose em caprinos e ovinos abatidos no matadouro público do município de Patos, na Paraíba.

\section{MATERIAL E MÉTODOS}

\section{Animais e colheita de amostras}

Foram utilizados caprinos e ovinos abatidos no matadouro público do município de Patos, semiárido da Paraíba, que apresentavam lesôes granulomatosas ou linfonodos hipertrofiados, em qualquer área, seja externa ou internamente, no período de novembro de 2008 a maio de 2009.

Dos animais que apresentaram qualquer lesão sugestiva de tuberculose, foram colhidos de maneira asséptica os próprios abscessos bem como os linfonodos acometidos, acondicionados em sacos estéreis individuais e encaminhados em caixa de isopor com gelo ao laboratório.

\section{Isolamento e identificação de micobactérias}

Os fragmentos de órgãos e lesôes colhidos para a bacteriologia foram mantidos sob refrigeração e encaminhados ao Laboratório de Zoonoses Bacterianas da Faculdade de Medicina Veterinária e Zootecnia da Universidade de Sáo Paulo (USP), onde foram processados visando ao isolamento de micobactérias. O procedimento consistiu na homogeneização das lesóes com posterior descontaminação pelo método de Petroff, semeadura nos meios de LöwensteinJensen e Stonebrink-Leslie, seguida de incubação a $37^{\circ} \mathrm{C}$ por até 90 dias (Centro Panamericano de Zoonosis, 1973). As colônias com características sugestivas de micobactérias foram fixadas em lâmina de vidro e coradas pelo método de Ziehl-Nielsen (Centro Panamericano DE Zoonosis, 1972) para pesquisa de BAAR (Bacilos Álcool-ácido Resistentes). Das amostras BAAR positivas foi utilizado o método de brometo de cetil-trimetilamônio (CTAB), segundo Kremer et al. (1999), para a purificação 
do DNA das micobactérias, seguida da identificação pelo método PRA (Telenti et al., 1993).

O método PRA consiste na utilização dos primers Tb11: (5'-ACCAACGATGGTGTGTCCAT) e Tb12: (5'-CTTGTCGAACCGCATACCCT), que amplificam um fragmento de $439 \mathrm{bp}$, caracterizando a amostra como pertencente ao gênero Mycobacterium, com posterior utilização de enzimas de restrição (BstEII e HaeIII), responsáveis por cortar o DNA em fragmentos com determinada sequência de bases. O produto destes cortes no DNA produz fragmentos de diferentes tamanhos, separados de acordo com o seu peso molecular, por eletroforese em ágar gel de alta resoluçâo, possibilitando, por meio de chaves de classificaçẫo, a diferenciação de espécies e subespécies de micobactérias (Telenti et al., 1993).

\section{Isolamento e identificação de outras bactérias}

O conteúdo caseoso das lesões foi semeado em ágar-sangue e incubado a $37^{\circ} \mathrm{C}$ em aerobiose. As placas eram examinadas após 24 a 48 horas (Sirva et al., 1982). Para a identificação dos agentes, utilizaram-se coloraçáo de Gram, provas bioquímicas e crescimento em meios seletivos como Ágar manitol, Sabouraud dextrose e MacConkey (Trabulsi; Alterthum, 2004).

\section{Exame histopatológico}

As amostras foram fixadas em formol tamponado a $10 \%$, clivadas e processadas rotineiramente para confecçáo de lâminas histopatológicas coradas com Hematoxilina e Eosina (HE) e Ziehl-Neelsen, seguindo-se a técnica de Behmer et al. (1976).

\section{RESULTADOS E DISCUSSÃO}

No presente trabalho, 40 animais foram estudados, dos quais 12 pertenciam à espécie caprina e 28 à ovina. Entre as amostras analisadas foram observadas lesóes nodulares bem delimitadas com material caseoso ao centro, distribuído focalmente, multifocalmente e coalescente, afetando fígado, pulmão, glândula mamária, bexiga e linfonodos mediastínicos, mesentéricos, submandibulares, parotídeos, poplíteos, pré-crural, pré-escapular e inguinal superficial. Em oito amostras as áreas centrais ao corte estavam enrijecidas e esbranquiçadas. Histologicamente, em 8 (20\%) animais, as lesóes foram caracterizadas como granulomas compostos por centro necrótico e focos de mineralização, margeados por camadas laminares constituídas por infiltrado inflamatório primeiramente de neutrófilos degenerados seguidos por macrófagos epitelioides, células gigantes e uma espessa lâmina de linfócitos e plasmócitos entremeados em tecido conjuntivo frouxamente organizado, delimitadas por uma cápsula densa de tecido conjuntivo (Figuras 1 e 2).

Dos 12 caprinos investigados, $1(8,33 \%)$ foi positivo no cultivo de micobactérias, e pelo método PRA o isolado foi classificado como pertencente ao complexo M. tuberculosis (Institut Pasteur, 2000) (Tabela 1), que compreende espécies patogênicas. Nas Figuras 3 a 5 são apresentados os resultados do PRA. Dado o número de caprinos utilizados $(\mathrm{n}=12)$, essa frequência

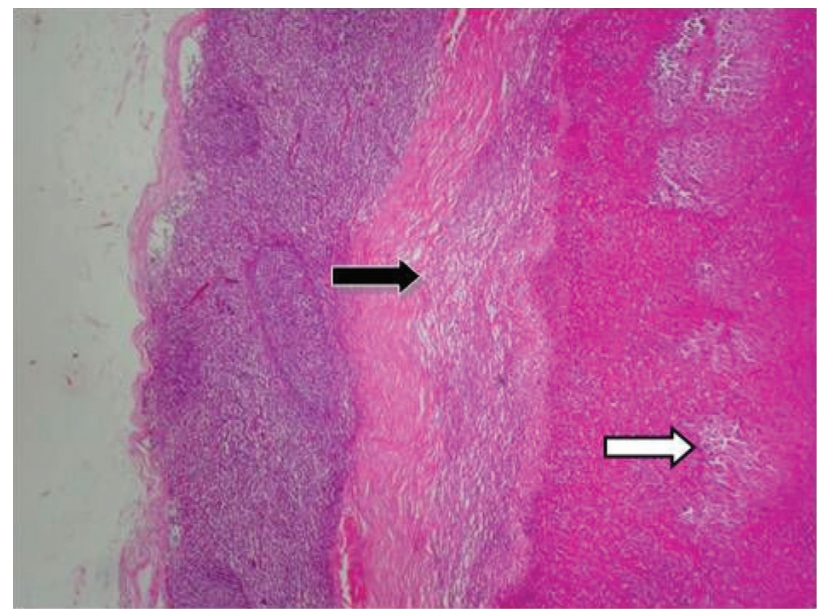

Figura 1. Linfonodo mediastínico. Observa-se área necrótica central com restos celulares e focos de mineralização (seta branca) seguida por camadas laminares de infiltrado inflamatório delimitado por uma densa cápsula de tecido conjuntivo (seta preta) comprimindo o tecido normal adjacente. Objetiva 20x. HE.

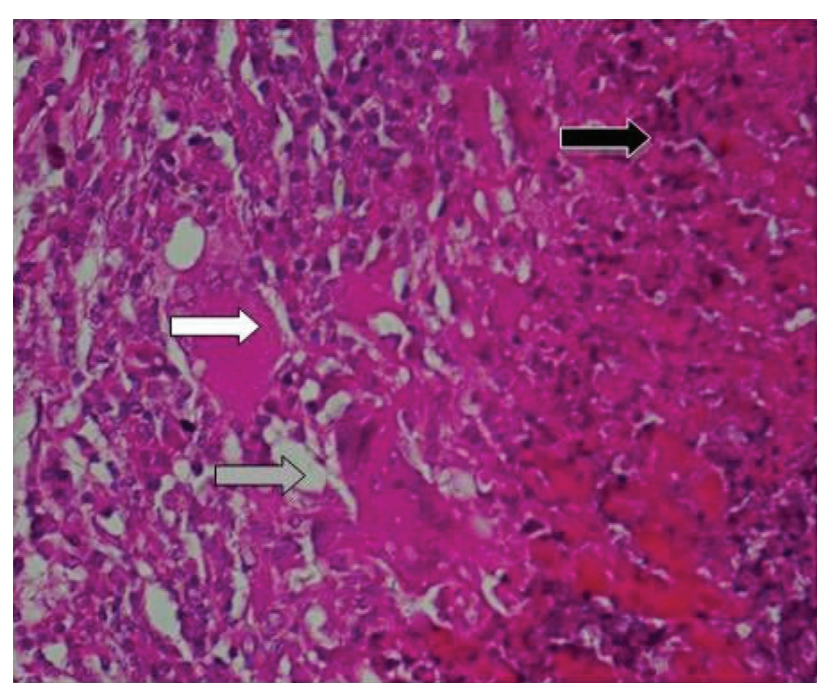

Figura 2. Linfonodo submandibular. Observa-se área necrótica margeada por infiltrado inflamatório de neutrófilos degenerados (seta preta), seguida por uma camada de macrófagos epitelióides (seta cinza) e células gigantes (seta branca). Objetiva 40x. HE. 
de infecçáo pode ser considerada alta e levanta preocupaçóes do ponto de vista de saúde pública, uma vez que se trata de uma importante zoonose, e indica que indivíduos que lidam diretamente com os animais e subprodutos, como tratadores e magarefes, estão expostos ao risco de infecção.

Soma-se a isso o fato de que a frequência real de animais infectados pode estar subestimada, pois, segundo Corner (1994), para bovinos, ela pode ser duplicada porque a inspeção de rotina só identifica cerca de $47 \%$ das lesôes macroscopicamente detectáveis. No presente trabalho, foram colhidas lesōes apenas de animais suspeitos, deixando-se de considerar animais que não apresentam lesóes sugestivas de tuberculose detectáveis ao exame post-mortem (BAPtista et al., 2004).

A tuberculose em caprinos, tida até pouco tempo como rara, também foi descrita no estado de São Paulo

Tabela 1. Micro-organismos isolados de gânglios hipertrofiados ou de lesões sugestivas de tuberculose em caprinos e ovinos abatidos no município de Patos (PB) no período de novembro de 2008 a maio de 2009.

\begin{tabular}{|c|c|c|c|}
\hline $\begin{array}{l}\text { Número } \\
\text { do animal }\end{array}$ & Espécie & Locais com lesões & Agente isolado \\
\hline 1 & Caprina & Glândula mamária & C. pseudotuberculosis \\
\hline 2 & Ovina & Linfonodo mesentérico & Crescimento ausente \\
\hline 3 & Ovina & Linfonodo pré-crural & C. pseudotuberculosis \\
\hline 4 & Ovina & Pulmão & C. pseudotuberculosis \\
\hline 5 & Caprina & Pulmão/linfonodo mediastínico & C. pseudotuberculosis \\
\hline 6 & Ovina & Fígado/linfonodo parotídeo & Crescimento ausente \\
\hline 7 & Ovina & Linfonodo pré-crural & C. pseudotuberculosis \\
\hline 8 & Ovina & Linfonodo pré-escapular & C. pseudotuberculosis \\
\hline 9 & Ovina & Pulmão/linfonodo parotídeo & Crescimento ausente \\
\hline 10 & Ovina & Linfonodo submandibular/parotídeo & C. pseudotuberculosis \\
\hline 11 & Ovina & Fígado & C. pseudotuberculosis \\
\hline 12 & Ovina & Fígado/pulmão & C. pseudotuberculosis \\
\hline 13 & Ovina & Fígado/pulmão/linfonodos mesentérico e mediastínico & C. pseudotuberculosis Micobactéria ambiental \\
\hline 14 & Caprina & Linfonodo mesentérico & C. pseudotuberculosis \\
\hline 15 & Ovina & Linfonodo pré-escapular & C. pseudotuberculosis \\
\hline 16 & Ovina & Fígado & C. pseudotuberculosis \\
\hline 17 & Ovina & Pulmão & C. pseudotuberculosis \\
\hline 18 & Ovina & Fígado & Crescimento ausente \\
\hline 19 & Caprina & Fígado/linfonodo mediastínico & C. pseudotuberculosis \\
\hline 20 & Ovina & Linfonodo inguinal superficial & C. pseudotuberculosis \\
\hline 21 & Caprina & Linfonodo mediastínico & C. pseudotuberculosis \\
\hline 22 & Ovina & Fígado & Crescimento ausente \\
\hline 23 & Caprina & Linfonodo pré-escapular & C. pseudotuberculosis \\
\hline 24 & Caprina & Linfonodo mediastínico & Crescimento ausente \\
\hline 25 & Caprina & Linfonodo pré-escapular & Crescimento ausente \\
\hline 26 & Caprina & Linfonodo mesentérico & Crescimento ausente \\
\hline 27 & Ovina & Pilar do diafragma & Crescimento ausente \\
\hline 28 & Caprina & Glândula mamária & Crescimento ausente \\
\hline 29 & Ovina & Fígado & Crescimento ausente \\
\hline 30 & Ovina & Bexiga & Crescimento ausente \\
\hline 31 & Caprina & Linfonodo submandibular & C. pseudotuberculosis Complexo M. tuberculosis \\
\hline 32 & Ovina & Fígado/linfonodo mediastínico & Crescimento ausente \\
\hline 33 & Ovina & Linfonodo parotídeo & C. pseudotuberculosis \\
\hline 34 & Ovina & Linfonodo poplíteo & C. pseudotuberculosis \\
\hline 35 & Ovina & Linfonodo parotídeo & C. pseudotuberculosis \\
\hline 36 & Caprina & Linfonodo parotídeo & C. pseudotuberculosis \\
\hline 37 & Ovina & Glândula mamária & Crescimento ausente \\
\hline 38 & Ovina & Linfonodo submandibular & C. pseudotuberculosis \\
\hline 39 & Ovina & Linfonodo parotídeo & C. pseudotuberculosis \\
\hline 40 & Ovina & Linfonodo submandibular & Micobactéria ambiental \\
\hline
\end{tabular}


por Benesi et al. (2008) em uma cabra da raça Saanen que apresentava lesôes sugestivas, sintomatologia clínica e positividade ao teste cervical comparativo, sendo o diagnóstico confirmado posteriormente com o isolamento e tipificação do M. bovis. Pinheiro et al. (2007) relataram um surto de tuberculose caprina em Minas Gerais, onde os animais reagentes à prova da tuberculina apresentaram lesóes sugestivas à necropsia e foram positivos no isolamento do agente. Pignata et al. (2009) usaram caprinos da microrregiáo do Cariri Ocidental paraibano e detectaram a presença de animais com lesóes compatíveis com tuberculose, bem como

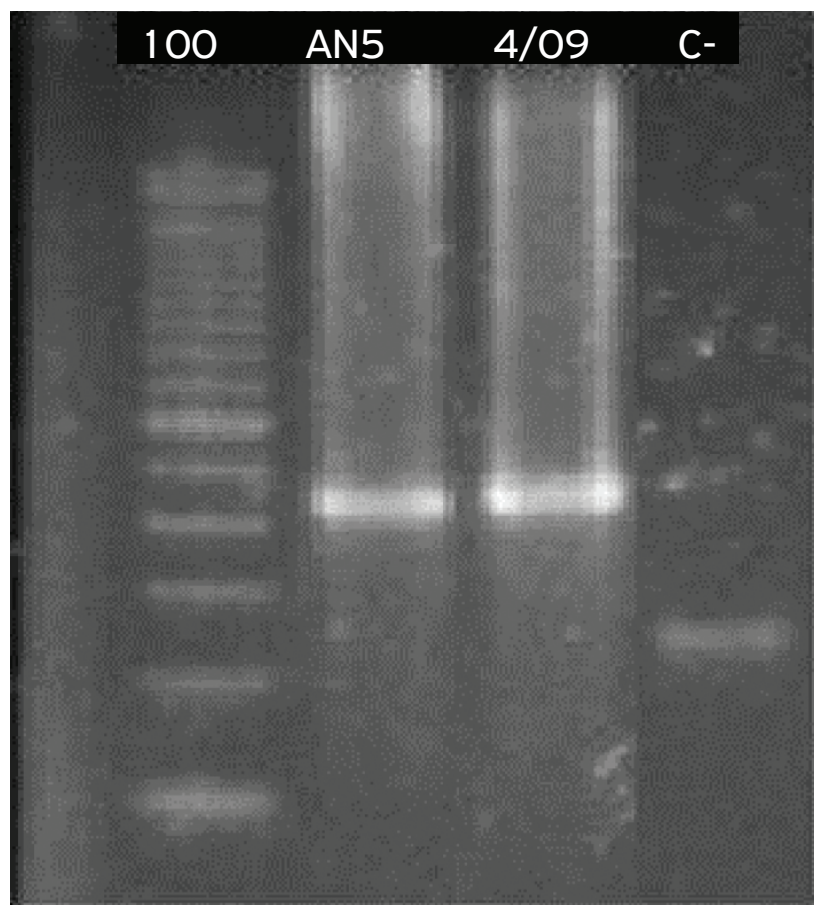

100: marcador molecular; AN5: amostra padrão; 4/09: amostra analisada; C-: controle negativo.

Figura 3. Resultado da eletroforese em gel de agarose mostrando a amplificação realizada com os primers Tb11 e Tb12, caracterizando a amostra como pertencente ao gênero Mycobacterium.

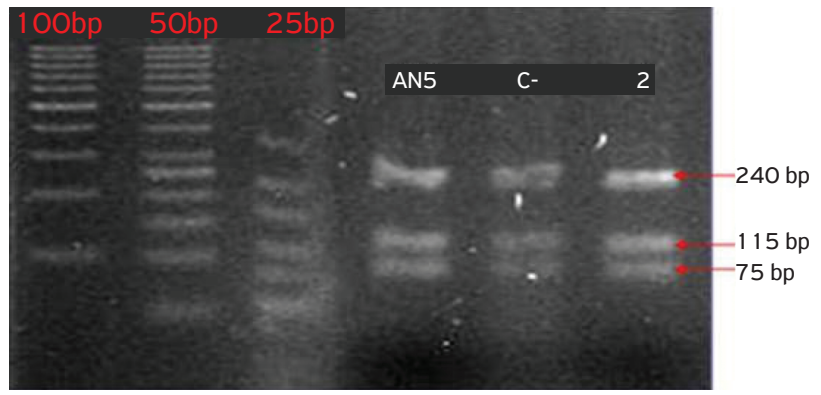

100, 50, 25: marcadores moleculares; AN5: amostra padrão; 2: amostra analisada; C-: controle negativo.

Figura 4. Eletroforese em gel de agarose mostrando fragmentos de 240, 115 e 75 bp gerados pela digestão do amplificado de 439 bp, específico do complexo Mycobacterium tuberculosis, pela enzima de restrição BstEll. isolaram micobactérias e identificaram a presença de bacilos álcool-ácido resistentes na baciloscopia direta.

Entre os 28 ovinos investigados, em 2 (7,14\%) foi confirmada a infecção por micobactérias ambientais (Tabela 1). Marcondes (2007) utilizou 57 ovinos da região de Pindamonhangaba e obtive isolamento de micobactérias em 7, sendo micobactérias ambientais em 6 e micobactérias do complexo $M$. tuberculosis em 1 animal. Uma possível explicação para a maior frequência de micobactérias ambientais em ovinos é que eles pastejam rente o solo, de maneira que a probabilidade de ingestão de micobactérias ambientais que têm como habitat o solo, água, poeiras e aerossóis (Falkinhan 3rd., 1996) é maior.

Dos caprinos pesquisados, houve isolamento de Corynebacterium pseudotuberculosis em 8 (66,66\%), com isolamento simultâneo de micobactérias e de C. pseudotuberculosis em 1 (8,33\%) animal. Já nos ovinos, registrou-se isolamento de C. pseudotuberculosis em 17 (60,71\%), também havendo isolamento simultâneo de micobactérias e de C. pseudotuberculosis em 1 (3,57\%) animal. Os achados foram semelhantes aos de Marcondes (2007), que detectou $3,5 \%(2 / 57)$ de isolamentos simultâneos do agente causador da linfadenite caseosa junto à micobactérias. Na mesma pesquisa, o autor verificou que os órgãos mais afetados foram o fígado, linfonodo submandibular, intestino, pulmão, linfonodo mediastino e glândula mamária, resultado semelhante ao do presente estudo, em que os órgãos mais afetados foram também o fígado e os linfonodos submandibulares.

Nos exames macroscópico e histopatológico, as lesôes por micobactérias ambientais e $C$. pseudotuberculosis não foram diferenciáveis das provocadas pelo complexo $M$. tuberculosis, tanto nos caprinos quanto nos ovinos, resultados igualmente encontrados por MARCONDES (2007), que referiu

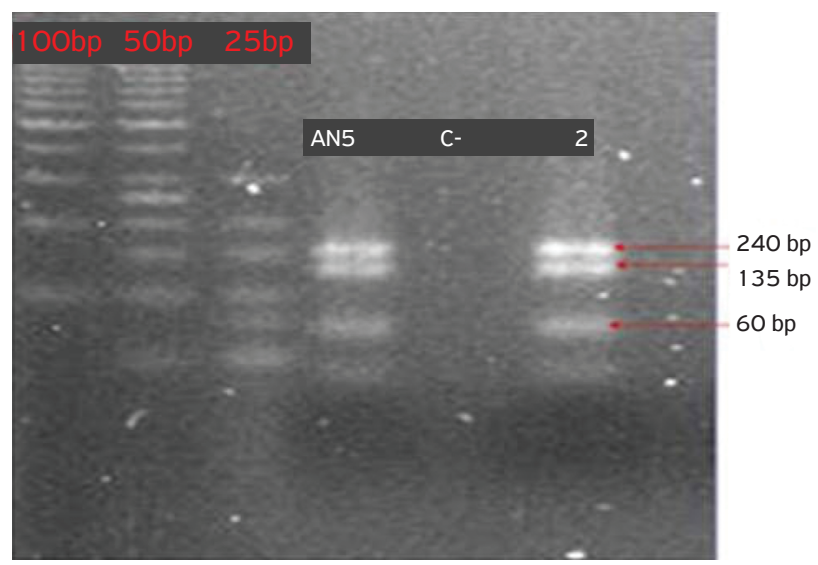

100, 50, 25: marcadores moleculares; AN5: amostra padrão; C-: controle negativo; 2: amostra analisada.

Figura 5. Eletroforese em gel de agarose mostrando fragmentos de 240, 135 e 60 bp gerados pela digestão do amplificado de 439 bp, específico do complexo Mycobacterium tuberculosis, pela enzima de restrição Haellı. 
que as lesóes causadas por $M$. flavescens $1, M$. kansasii e $C$. pseudotuberculosis não puderam ser diferenciadas. No Brasil, a linfadenite caseosa dos ovinos e caprinos é importante para os criadores em decorrência das perdas econômicas, e está amplamente disseminada nas criaçóes (RIET-Correa et al., 2001). Devido às lesóes causadas por C. pseudotuberculosis serem semelhantes às causadas por micobactérias, há a necessidade de se aprimorar o diagnóstico diferencial entre as duas infecçóes (Marcondes, 2007).

A ausência de micobactérias ocorrida em 37 (92,5\%) das amostras com lesóes típicas ou sugestivas de tuberculose pode estar associada, segundo BALIAN et al. (1997), a três hipóteses: deficiência do método de isolamento com morte na descontaminação ou dificuldade de se multiplicar no cultivo, a morte das micobactérias após promover a lesão, pela defesa do próprio organismo, ou a lesão causada por outro tipo de micro-organismo. O gênero Mycobacterium é altamente exigente no que se refere a nutrientes, quando comparado a outras bactérias patogênicas, como Staphylococcus aureus, Salmonella spp., Escherichia coli e outras enterobactérias. Tais características facilitam a multiplicação anterior de contaminantes menos exigentes, tornando indispensável a aplicação de um tratamento das amostras previamente à tentativa de isolamento das micobactérias (BALIAN, 2002).
Conforme Gutiérrez (1995) e Ramirez (2003), os caprinos são mais suscetíveis à tuberculose, por isso têm sido apontados como um bom modelo animal para estudos de patogenicidade e patologia da tuberculose e para a avaliação de novas vacinas. Os autores reforçam ainda que pesquisas moleculares e o desenvolvimento de novas vacinas sáo imprescindíveis para a erradicação da tuberculose caprina.

\section{CONCLUSÃO}

O isolamento de micobactéria do complexo $M$. tuberculosis em caprinos abatidos no semiárido da Paraíba, bem como a detecção de micobactérias ambientais em ovinos, levanta preocupaçóes do ponto de vista de saúde pública, uma vez que profissionais envolvidos na manipulação desses animais e a população consumidora da carne e leite estáo expostos ao risco de infecção. Dessa maneira, é importante a conscientização por parte das autoridades sanitárias acerca da implantação de medidas de prevenção adequadas com o objetivo de impedir, ou pelo menos diminuir, a disseminação da tuberculose em caprinos e, consequentemente, bloquear a possível transmissão do agente para os seres humanos.

| || | | | | | | | | | | | | | | | | | | | | | | | | | | | | | | | | | | | | | | | | | | | | | | | | | | | | | | | | | | | | | | | | | | | | | | | | | | | | | | | | | | | | | | | | | | | | | | | | | | | | | | | | | | | | | | | | | | | | | | | | | | | | | | | | | | | | | | | | | | | | | | | | | | | | | | | | | | | | | | | | | | | | | | | | | | | | | | | | | | | | | | | | | | | | | | | | | | | | | | | | | | | | |

\section{REFERÊNCIAS}

BALIAN, S.C.; PINHEIRO, S.R.; GUERRA, J.L.; MORAIS, Z.M.; FERREIRA, F.; FERREIRA NETO, J.S. Estudo comparativo de dois métodos de descontaminação na pesquisa de micobactérias. Arquivo Brasileiro de Medicina Veterinária e Zootecnia, São Paulo, v.69, n.2, p. $11-14,2002$.

BALIAN, S.C.; RIBEIRO, P.; VASCONCELLOS, S.A.; PINHEIRO, S.R.; FERREIRA NETO, J.S.; GUERRA, J.L; XAVIER, J.G.; MORAIS Z.M.; TELLES, M.A.S. Linfadenites tuberculóides em suínos abatidos no Estado de São Paulo, Brasil: aspectos macroscópicos, histopatológicos e pesquisa de micobactérias. Revista de Saúde Pública, São Paulo, v.31, n.4, p.391-397, 1997.

BAPTISTA, F.; MOREIRA, E.C.; SANTOS, W.L.M.; NAVEDA, L.A.B. Prevalência da tuberculose em bovinos abatidos em Minas Gerais. Arquivo Brasileiro de Medicina Veterinária e Zootecnia, São Paulo, v.56, n.5, p.577-580, 2004.

BEHMER, O.A.; TOLOSA, E.M.C.; FREITAS NETO, A.G. Manual de técnicas para histologia normal e patológica. São Paulo: EDUSP, 1976. $241 \mathrm{p}$.

BENESI, F.J.; PINHEIRO, S.R.; MAIORKA, P.C.; SAKAMOTO, S.M.; ROXO, E.; BENITES, N.R.; BIRGEL JUNIOR, E.H.; GREGORY, L.
Relato de caso: tuberculose em caprino (Capra hircus). Arquivos do Instituto Biológico, São Paulo, v.75, n.2, p.217-220, 2008.

BRASIL. Instituto Brasileiro de Geografia e Estatística. Sistema IBGE de Recuperação Automática - SIDRA. Pesquisa Pecuária Municipal, 2007. Disponível em: <http://www.sidra.ibge.gov.br/bda/tabela/ listabl.asp?c=73\&z=t\&o=20>. Acesso em: 19 ago. 2009.

BRITO, M.A.; GONZÁLES, F.D.; RIBEIRO, L.A.; CAMPOS, R.; LACERDA, L.; BARBOSA, P.R,; BERGMANN, G. Composição do sangue e do leite em ovinos leiteiros do sul do Brasil: variações na gestação e na lactação. Ciência Rural, v.6, n.3, p.942-948, 2006.

CENTRO PANAMERICANO DE ZOONOSIS. Diagnóstico de laboratorio de la tuberculosis animal. Buenos Aires: CPZ, 1972. 48p.

CENTRO PANAMERICANO DE ZOONOSIS. Métodos de laboratorio de micobacteriologia veterinaria para el aislamiento e identificación de micobacterias. Buenos Aires: Panamerican Health Organization, 1973. 48p.

CORDEIRO, R.C. O desenvolvimento econômico da caprinocultura leiteira. Revista do Conselho Federal de Medicina Veterinária, n.13, p.28-30, 1998. 
CORDES, D.O.; BULLIANS, J.A.; LAKE, D.E.; CARTER, M.E. Observations on tuberculosis caused by Mycobacterium bovis in sheep. New Zealand Veterinary Journal, v.29, n.4, p.60-62, 1981.

CORNER, L.A. Post mortem diagnosis of Mycobacterium bovis infection in cattle. Veterinary Microbiology, v.40, n. 1-2, p.53-63, 1994.

CORRÊA, O. Doenças infecciosas dos animais domésticos: doenças causadas por bactérias e fungos. Rio de Janeiro: Freitas Bastos, 1975.61p.

FALKINHAN 3rd J.O. Epidemiology of infection by nontuberculosis mycobacteria. Clinical Microbiology Reviews, v.9, n.2, p.177-215, 1996.

GUTIÉRREZ, M.; SAMPER, S.; GAVIGAN, J.A.; GARCIA Marín, J.F.; MARTÍN, C. Differentiation by molecular typing of mycobacterium bovis strains causing tuberculosis in cattle and goats. Journal of Clinical Microbiology, v.33, n.11, p.29532956, 1995.

INSTITUT PASTEUR. Identification of mycobacteria. 2000. Disponível em: <http://app.chuv.ch/prasite/index.html>. Acesso em: 25 nov. 2008.

KREMER, K.; VAN SOOLINGEN, D.; FROTHINGHAM, R.; HAAS W.H.; HERMANS, P.W.M.; MARTIN, C.; PALITTAPONGARNPIM, P.; PLIKAYTIS, B.B.; RILEY, L.W.; YAKRUS, M.A.; MUSSER, J.M.; VAN EMBDEN, J.D.A. Comparison of methods based on different molecular epidemiological markers for typing of Mycobacterium tuberculosis complex strains: interlaboratory study of discriminatory power and reproducibility. Journal of Clinical Microbiology, v.37, n.8, p.2607-2618, 1999.

LANGENEGGER, J.; LANGENEGGER, C.H.; SCHERER, P.O. Prevalência e diagnóstico comparativo da linfadenite caseosa em caprinos do estado do Rio de Janeiro. Pesquisa Veterinária Brasileira, v.11, n.1/2, p.31-34, 1991.

MARCONDES, A.G. Micobacteriose em ovinos (Ovis aries) do Estado de São Paulo, Brasil. Correlação entre teste imunoalérgico, cultivo e histopatológico. 2007. 93f. Tese (Doutorado em Medicina Veterinária) - Faculdade de Medicina Veterinária e Zootecnia - Universidade de São Paulo, São Paulo, 2007.
PIGNATA, W.A.; ALVES, C.J.; AZEVEDO, S.S.; DANTAS, A.F.M.; GOMES, A.A.B.; REMÍGIO, F.R.; LIMA, F.S. Prevalência da tuberculose caprina no semi-árido paraibano. Pesquisa Veterinária Brasileira, v. 29, n. 7, p. 526-532, 2009.

PINHEIRO, S.R.; ROXO, E.; ALMEIDA, C.A.S.; VASCONCELLOS, S.A.; SILVANTOS, M.C.; MAIORKA, P.C.; MELVILLE, A.M.P.; BENITES, N.R.; PAES, A.C. Surto de tuberculose em caprinos (Capra hircus): relato de caso. In: ENCONTRO NACIONAL DE PATOLOGIA VETERINÁRIA, 13., 2007, Campo Grande, MS. Resumos. Campo Grande: 2007. p. 13-34.

QUINTANS, L.J. Estudo de mercado e de localização - Usina de Desidratação de Leite de Cabras. Microrregião homogênea do Cariri Ocidental. Plano de Desenvolvimento Local Integrado. João Pessoa, 1995. 104p.

RAMIREZ, I.C.; SANTILLAN, M.A.; DANTE, V. The goat as an experimental ruminant model for tuberculosis infection. Small Ruminant Research, v.47, n.2, p.113-116, 2003.

RIET-CORREA, F.; SCHILD, A.L.; MÉNDEZ, M.D.C.; LEMOS, R.A.A. Doenças de ruminantes e equinos. São Paulo: Livraria Varelsa, 2001.

SILVA, R.R. Agribussiness do leite de cabra. Salvador: SEBRAE, 1998.

SILVA, S.F.; SANTOS, A.F.; LAUZER, J.J.; COSTA, D.F. Linfadenite caseosa em caprinos na região do sertão de Pernambuco, Brasil. In: CONGRESSO BRASILEIRO DE MEDICINA VETERINÁRIA, 14. 1982, São Paulo, SP. Anais. São Paulo: 1982. p.155.

TELENTI, A.; MARCHESI, F.; BALZ, M.; BALLY, F.; BÖTTGER, E.C.; BODMER, T. Rapid identification of mycobacteria to the species level by polymerase chain reaction and restriction enzyme analysis. Journal of Clinical Microbiology, v.31, n.2, p.175-178, 1993.

THOEN, C.; LOBUE, P.; KANTOR, I. The importance of Mycobacterium bovis as a zoonosis. Veterinary Microbiology, v.112, n.2-4, p.339-345, 2006.

TRABULSI, L.R.; ALTERTHUM, F. Microbiologia. Rio de Janeiro: Atheneu, 2004 